\title{
Exploring the Factors Affecting Employee's Satisfaction in Non-Government Organizations (NGOs) of Bangladesh: An Experience from Bangladesh Rural Advancement Committee (BRAC)
}

\author{
Mohammed Mahin Uddin', Md. Zia Uddin², Rajesh Paul', Tajdar Khan'1, Sumran Ali ${ }^{*}$ \\ ${ }^{1}$ School of Public Affairs, University of Science and Technology of China, Hefei, China \\ ${ }^{2}$ Comilla University, Comilla, Bangladesh \\ Email: ^Sumranali@mail.ustc.edu.cn
}

How to cite this paper: Uddin, M.M., Uddin, Md.Z., Paul, R., Khan, T. and Ali, S. (2019) Exploring the Factors Affecting Employee's Satisfaction in Non-Government Organizations (NGOs) of Bangladesh: An Experience from Bangladesh Rural Advancement Committee (BRAC). Open Journal of Social Sciences, 7, 1-23.

https://doi.org/10.4236/jss.2019.78001

Received: July 6, 2019

Accepted: August 4, 2019

Published: August 7, 2019

Copyright $\odot 2019$ by author(s) and Scientific Research Publishing Inc. This work is licensed under the Creative Commons Attribution International License (CC BY 4.0).

http://creativecommons.org/licenses/by/4.0/

\begin{abstract}
The paper contributes to research on employee satisfaction theory through analysing relationship between Job security (JS), job innovativeness (JI), internal communication (IC) and compassion \& self-sacrifice (CSS) as antecedents of employee's satisfaction (ES) in NGOs sectors in Bangladesh, and the moderating role of education $\&$ training (ET) in this relationship. The conceptual framework is examined using structural equation modelling. Data analysed has been drawn from 260 employees of BRAC NGOs located in Comilla and Chandpur districts of Bangladesh. The findings of this research positively strengthen the Non-government Organizations (NGOs) of Bangladesh with providing the job satisfaction to the employee by exploring the antecedents of employee's satisfaction in NGOs. These outcomes of the study are consistent with the conclusion that employers of NGOs working in Bangladesh should cordially focus on employee's satisfactory factors for the sake of assuring better performance and productivity.
\end{abstract}

\section{Keywords}

Employee Satisfaction, The Theory of Employee Satisfaction, NGOs, BRAC, Bangladesh

\section{Introduction}

NGOs have long working experience in Bangladesh and just immediately after 
the liberation war (1971); it emerged with rehabilitation activities for the post-war destitute people. Inexactly, 16,000 NGOs in 50,000 villages are working in Bangladesh in order to assist near about 40 lakh families and a total 233 foreign NGOs from 27 countries are operating their activities in this country [1], focusing on poverty, education, health \& family planning, women empowerment, environment, self-employment and disaster [2]. In spite of having a long successful history of NGOs in Bangladesh in foresaid fields but these NGOs face many challenges and in some cases, they cannot be affordable to succeed. Out of many problems, NGOs mostly suffer from fundraising, distrust from donors, and lack of skilled human resources [3]. Cooperation between NGOs and services receiving organizations/individuals is one of the major organizational obstructs for NGOs working in Bangladesh [4]. Islamic traditions and customs are preserved by Ulama community of the country those who figure out that existing NGOs are the reflection of western dominance in Bangladesh. Communication with other NGOs, donors, government agencies, and other relief organizations is a barrier for NGOs in this country [5].

However, from the legal perspective, NGOs in Bangladesh are encountering a few challenges and relaxations. Broadly, there are two sorts of regulatory systems of NGOs in Bangladesh like laws for NGOs formation and laws for regulating NGOs' activities, and a total 12 laws act for NGOs formation and operation in Bangladesh. Maximum laws for NGOs operation \& regulation are archaic, mainly of the 19th century, and due to infirm legal structure, several NGOs suffer from poor administration. The most prominent laws for NGOs' activities in this country are-the Societies Registration Act of 1860, the Trust Act of 1882 and the Companies Act of 1913. The NGOs work on human rights, advocacy, and tribal people-are monitored sensitively with the help of some black laws \& executive orders.

The current study comprises the lessons learns from one of the very noticeable NGOs named BRAC. In consideration of the number of staffs BRAC (Bangladesh Rural Advancement Committee) is the most prominent Non-government organization in the world with having 120,000 employees in 14 countries, including Bangladesh. After soon of liberation war 1971, Fazle Hasen Abed founded BRAC in 1972 for economic and social development of the war affected poor Bangladeshi people and at present its approximate total beneficiary individuals are 126 million [6], and the values of BRAC's programs have a direct impact in the rural society of Bangladesh.

In Bangladesh, the majority of NGOs are not succeeded in terms of service delivery and cost minimization. Along with, many challenges like a fund, skilled human resources, tight rules and regulation, poor governance, and recently employee's dissatisfaction has been added as the great challenges to NGOs sector. The consequences of this employee dissatisfaction cause low organizational outcomes. Many NGOs particularly, medium and small size ones are facing massive troubles in the operation of daily activities. Some Prior studies, [7] and [8] investigated that employee's dissatisfaction is principally responsible in this re- 
gard. Employee satisfaction is just the opposite of employees' dissatisfaction. Therefore, the significance of employee's satisfaction in NGOs sectors has been scaled up in the context of Bangladesh. According to [9], for effective employee's plan and customer contentment, employee's satisfaction plays a vital role in private organization.

Further, [10] examined that employees' satisfaction is significant for far-reaching growth as well as expected outcomes of the company. Employee job satisfaction is supremely important in an organization because it is what productivity depends on? That study added that employees are the core resources of the organization and their departure effects significantly in a negative way, the implementation process of the business plan. The results of the researches [11] [12] supported that job satisfaction is a pre-condition for work performance and similarly, a previous study explored that the relationship between work performance and job satisfaction is not unambiguous as well as unexpected [13]. Many prior researches in different contextual aspect reported that a relevant and negative relationship exists between job satisfaction and employee turnover [14] [15]. The studies further focused that the rate of job leaving by dissatisfied employees is higher than satisfied employees. The findings of the study indicated that higher employee satisfaction notably diminishes job stress and turnover intention among nurses in Taiwan [16]. Some researchers figure out that employee's satisfaction leads to affect work productivity, employee's turnover, and absenteeism. Job satisfaction is not only crucial for organizational performance, but also it leads to an individual's well-being of the employees. Moreover, employee satisfaction is considered as the strong predictor of undertaking decision to stay in organization permanently [17].

[18] defined job dissatisfaction as "unpleasant condition and feeling of the employees that result in lower job performance to withdrawal behaviours as absenteeism or turnover." Job dissatisfaction causes labour turnover intention and ill health, resulting in the low productivity and outcomes that lead to the organization to the risk of sustainability [19] [20]. [20] investigated the key causes of employee's dissatisfaction that pushes the employees to turnover. It also argued that this turnover assists the human resources management to predict regarding actual satisfactory factors of employees. Some previous studies showed that job satisfaction is a momentous factor for management because dissatisfaction causes poor performances or productivity [13] [21], and low efficiency and leads to higher employee turnover [22] [23] [24]. By [25], the dissatisfaction of women employee in garments industry spreads promptly to their workmates that damages the goodwill of the industry. Due to dissatisfaction among employees especially in privates sectors encourages the employees to search new job and finally decline the productive capabilities of employees, break down their morale and concentration towards work is decreased dramatically [3]. Insufficient payment, less training and development facilities and lack of supervision and monitoring are mostly responsible for an employee being dissatisfied, and this dissatisfaction leads to leaving the organization [20] [26] revealed that em- 
ployee retention is the topmost challenges for manufacturing and industry in Irish. The employee dissatisfaction in garments sectors in Bangladesh entangles the production and accelerates the cost of production. A previous study conducted targeting employee satisfaction in higher education [27], regarded employee as the internal clients of the business and the desire to cooperate in fulfilling the objectives of the business and the study also explored that employee's satisfaction influences organizational performance. The study further illustrated that teachers are the employees of educational institute and teachers' satisfaction about works promotes the best lecture delivery and research quality. Anita (2012) pointed out that dissatisfied employees are seemed to be less creative, productive, and committed to the owners of the organization. Although, many studies from developed and developing countries focused on job satisfaction/ employee satisfaction of government organization, garments, banks, manufacturing, educational institutes but very few studies emphasized on employee satisfaction of NGOs.

Hence, the present study aims to analyse critical factors affecting employee's satisfaction in NGOs sectors in Bangladesh. The authors also modelled the moderating effect of education \& training on employee's satisfaction with (job security, internal communication, job innovativeness, and compassion \& self-sacrifice). More specifically, the study emphasized on the following questions: 1) how does education \& training effect on employee satisfaction? 2) What is the relationship between (job security, internal communication, job innovativeness, and compassion \& self-sacrifice)? 3) Does education \& training moderate relationship on employee satisfaction and (job security, internal communication, job innovativeness, and compassion \& self-sacrifice? The current research brought forward several theoretical contributions such as it explores how four factors (job security, internal communication, job innovativeness, and compassion \& self-sacrifice) effect to employee satisfaction by bluntly considering the essence of employee satisfaction theory.

\section{Literature Review}

\section{Employee Satisfaction}

In organizational research and human resources management, employee satisfaction is studied with most importantly in recent years. Satisfaction is the state of happiness of mind. Employee or job satisfaction is the extent of happiness feeling of employees about job and employer. Job satisfaction explores emotional feeling and responses to their job and organization [11]. Marketing culture' components like (innovativeness, selling task, and service quality) have a significant effect on employees' distinct satisfaction [28]. Employee's satisfaction is positively influenced by some HR issues like training, compensation, employee development [29]. For boosting organizational culture as well as employees satisfaction the composition of the work environment, freedom of work, recognition \& reward with accurate organizational setup will be the most prioritized is- 
sues [30]. Authors showed that teamwork, motivation, and professional pressure have a positive relationship with employee satisfaction in Jordanian public hospital. By [31], employees' job satisfaction is influenced by distributive justice, environment, and work motivation. The finding reveals that recognition and training and development are positively associated with employee job satisfaction, whereas reward did not have a significant impact on employee job satisfaction [32]. Job satisfaction is more focused on the individual's response to the job or specific aspects of the job, such as pay, supervision, and working conditions [33]. Among the dimensions of job satisfaction, the compensation package is regarded as the most influential factor of job satisfaction for employees of any organization [34]. Nine facets associated with job satisfaction like pay, promotion, supervision, fringe benefits, contingent rewards, operating conditions, co-workers, nature of work and communication, was explored by [35].

The study showed that the job satisfaction is found to be averagely satisfied, and accommodation level, administration, work condition, recognition, co-workers communications, educational activity, payment, vacation, and leaves are used to determine the job satisfaction to the nurses of Al-Qassim hospital of Sudia Arabia [36]. The research used the MUSA method that showed the richness of the set of factors which determine the satisfaction of newly recruited personnel at work in a large French organization [37]. Martin \& Kaufman (2013) investigated that there is a strong positive correlation between organizational climate and the dependent variable of job satisfaction in South African Information \& Technological organization. Work employment, Employee relationship, and training influence on job satisfaction of Bangladesh government Sonali Bank's employees [38]. The employees and executives of public sector banks are more satisfied in the job than the employees, nonexecutives of private sector banks in Bangladesh [39]. The compensation package, supervisory support, job security, training and development opportunities, team cohesion, career growth, working conditions, and organizational culture and policies are positively associated with the academics' job satisfaction in Bangladeshi private universities [40]. Training and performance appraisal, work atmosphere, compensation package, supervision are the key factors that impact on employees' job satisfaction of Grameen Phone (GP), Bangla Link and Aktel mobile companies in Bangladesh [41]. Although there are some studies on NGOs' performance, governance, development works and sustainability, but none of the studies in Bangladeshi literature investigated the present status of employee's job satisfaction in NGOs sector in Bangladesh, hence, this present study.

\section{Theoretical Framework}

The research adopted the theory of employee satisfaction, a model of [42]. The main focus point in this research is to explore the influence of some factors on employee's satisfaction with BRAC NGO. Job satisfaction is a relative term, and it is varied from employee to an employee for the variation of their expectation, 
beliefs, values, norms. Even, due to the nature of organizations (public, private, profit \& non-profit, business, economical), employee's satisfaction is varied. Organizational, cultural, social, environmental, behavioural factors are also responsible for bringing satisfaction among employees. Many studies have been done on employee's job satisfaction using employee satisfaction model. Personal and demographic factors (race, education, age, sex, tenure and work experience) and psychological factors (emotional intelligence, perception of the goal-settings process and personality characteristics) effect on employee job satisfaction in different arena of business and economics sectors [43]-[49].

Oshagbemi (1996)identified the following (teaching, research, administration and management, present pay, promotion, supervision, behaviours of co-workers, physical condition and working facilities) factors for job satisfaction of 566 colleges teachers. Content of work, supervision, co-workers, promotion, pay, and security were identified as the factors of employee satisfaction to the female employee in the Kuwaiti public government sector [50]. Another group of scholars suggested on some individuals factors like (salary, nature of work, leadership, promotion, colleagues, etc.) as the satisfactory factors of employees of a various private organization [51] [52] [53] [54]. Therefore, we are proposing the theoretical framework with the relationship of job security, internal communication, job innovativeness, compassion \& self-sacrifice and employee's satisfaction (see Figure 1).

\section{Hypothesis Development}

\subsection{Job Security (JS) and Employee’s Satisfaction (ES)}

By [55], Job security does not refer to merely the loss of job of an employee's rather it suspects whether an employee will be affordable to manage job further shortly or not? [40] investigated that job security is an important factor in Bangladesh for satisfying employees' in a job because of tremendous rate of unemployment. Low job security is inclusively associated with low job satisfaction in private doctors of Bangladesh [56]. A study on cooperative extension suggested that it is more productive employees those who feel the security of job comparatively with whom feel secured of the job [57]. Many prior studies in the field of

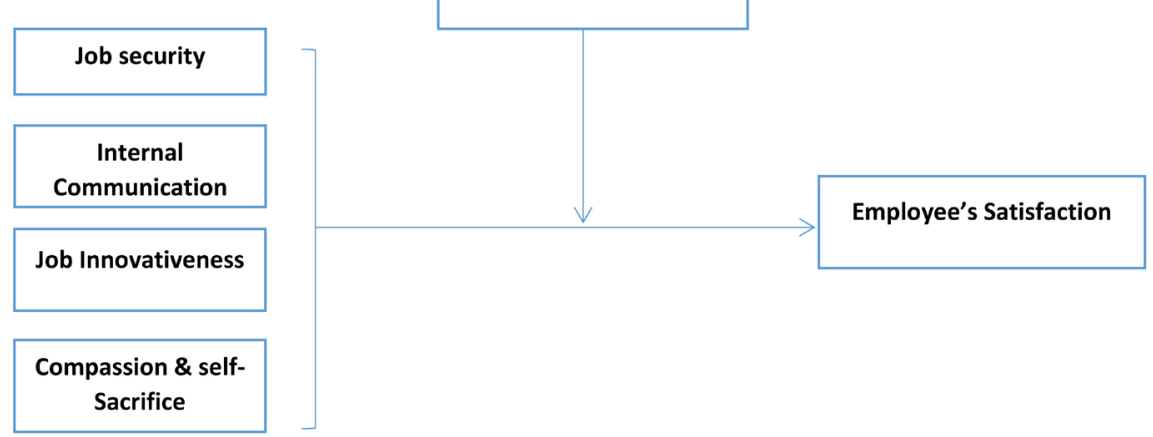

Figure 1. Theoretical framework. 
economics \& business identified that job security is the pivotal antecedent for job satisfaction in an organization [58] [59]. In a study conducted among 1000 respondents of Germany, Luxembourg, and the United Kingdom [59], explored that job security is positively correlated with employee's job satisfaction. [60] found that higher job satisfaction depends on higher job security and the relationship between employee satisfaction and job security are measured based on unemployment. Therefore this study proposed the following hypothesis.

$H_{1}$ : The higher "Job Security" (JS) increases the "Employee's Satisfaction" (ES) in the case of NGOs.

\subsection{Internal Communication (IC) and Employee's Satisfaction}

The author found that communication between employees and top management is one of the best contributions to job satisfaction in public sector organization (Lehman, 2014). Co-worker communication is regarded as the most significant determinate factor for job satisfaction in Al-Qassim hospital in Saudi Arabia [36]. Significant and inclusive relationship between job satisfaction and internal communication is proved by previous some studies [61] [62] [63] in various contexts. According to [64], communication has strong and positive relationship with employees satisfaction, and communication-satisfaction interconnection is a symptomatic part of organizational success. Two different studies from Bangladesh context emphasized on communication as an antecedent of employee's satisfaction in a private organization [65] [66]. Considering the literature above the following hypothesis is proposed:

$H_{2}$ : The higher constructive "Internal Communication" (IC) increases the "Employee's Satisfaction" (ES) in NGOs.

\subsection{Job Innovativeness (JI) and Employee's Satisfaction}

Innovativeness is a continuous \& spontaneous organizational process that happens overtime to meet up new challenges, and it has a far-reaching effect on social \& economic as well as a business change of contemporary globe [30]. Innovativeness is a large conception which denotes the intention to incept new idea, service as well as a product through organizational system, procedure, and process to enhance the potential of organizational better performance [67]. Innovativeness is a crucial element of marketing culture that significantly impact on job satisfaction [28]. A previous study conducted among 191 respondents in Malaysian electronic and electrical (E \& E) manufacturing firms showed that job satisfaction and job intensity is positively-negatively influenced by green products and process [68]. Review of prior literature established reasonable evidence to back up the significant relationship between job satisfaction and innovativeness in developed as well as developing countries from various perspectives [69] [70] [71]. Therefore, the study proposed to test the following hypothesis.

$H_{3}$ : The higher "Job Innovativeness" (II) increases the "Employee's Satisfaction" (ES) in NGOs in the case of Bangladesh. 


\subsection{Compassion and Self-Sacrifice (CSS) and Employee's Satisfaction}

Compassion is defined as a "deep sense or quality of knowledge of the suffering of another, coupled with the wish to relieve it and it is associated with feelings of condolence, pity, sympathy, empathy, and commiseration" [72]. Self-compassion is meaningfully and independently associated with happiness and well-being in healthcare professionals [73]. Compassion competence was a factor influencing compassion satisfaction and burnout in the professional quality of life [74]. Generally, self-sacrifice is the dedication something for the greater sake of others or giving up self-interests for others. Compassion and self-sacrifice are the most important antecedent issues, and employees' sense of Self-Sacrifices as a part of PSM (SS) increases Job Satisfaction among employees [75]. A study on public service modification investigated that motivational needs like self-service acts as an antecedent for employee satisfaction [76]. Self-sacrifice is the influencing element for public service motivation, employee satisfaction and public service motivation is positively connected [77]. Hence, the proposed hypotheses are as following:

$H_{4}$ : The higher degree o "Compassion" (Com) increases the "Employee's Satisfaction" (ES) in NGOs.

$H_{5}:$ The greater value of "Self Sacrifice" (SS) increases the "Employee's Satisfaction" (ES) in NGOs in Bangladesh.

\subsection{Moderating Effect of Education \& Training (ET)}

Education accelerates worker's skills, and it also assures the higher salary for employees resulting in employee satisfaction. Education is the process of learning, and mostly, it is crucial for social-economics and national prosperity [78]. Education and leadership are the factors that influence job satisfaction among nurses of Jordanian public hospitals, cited in. Some previous empirical studies of developed and developing countries having a variety of context [79] [80] [81] proposed by [82], showed that education influence on employee's job satisfaction. Turkey tourism industry explored that strong ties exist between education level and employees satisfaction by [83]. Similarly, another study on Bangladeshi academician proved that training and development policies are positively associated with job satisfaction [40]. Training is an instrument for transferring work related specific knowledge to foster employee's performance. "Training is methods that are applied to provide the new employees with the skills needed to perform their jobs" [84]. According to [29], Training and development are positively related to employee satisfaction. Training and education become a prominent part of the employee's satisfaction, and these affect the overall job satisfaction level of organization [85]. Review of many previous empirical literatures highlighted evidence that employee training significantly brings employee job satisfaction in different organizations in their respective contexts [34] [86] [87]. The findings disclose that education and training are Corley 
associated with employee's satisfaction in both public and private organization of developed and developing countries. Therefore, the study attempts to investigate the presence of education \& training as a moderator relationship between employee's satisfaction and (job security, internal communication, innovativeness, compassion). Hence, the study proposes the following hypothesis to test.

$H_{6}$ : the attribute of "Training and Education" moderates the determining power of "job characteristics" (Job innovativeness, Job security and Internal communication) and "public service motivational factors" (self-sacrifice and compassion) while defining and explaining "Employees satisfaction" (ES).

\subsection{Dependent Variable: Employee’s Satisfaction (ES)}

"Employee satisfaction has most often been defined as a pleasant or positive emotional state resulting from the perception of work, conception, and assessment of the work environment, work experience and the perception of all elements of the work and workplace" cited in [1]. The ingredients of a job have the various extent of significance that can be used for measuring overall satisfaction of employees from different ways in the organization [88]. Previous researches focused on many factors in different ways as well as contexts for employee/job satisfaction but broadly emphasized on job security, education and training, communication, compensation, innovativeness, compassion, working condition, service quality [28] [60] [89] [90]. Employees' satisfaction depends mostly on internal communication and training \& development in European private voluntary organization [87]. Moreover, a study [91] conducted in Telecommunication Company of East Azerbaijan having sample 240 revealed that employee's learning satisfaction relies on significantly on four variables like technology, educational content, motivation, and attitude. Furthermore, Banibakr et al. (2019) suggested that nurses' satisfaction of public hospital in Jordan relies on some organizational factors like work environment, organizational assurance, level of education and leadership, nurses' teamwork, motivation, benefit, salary, and employment opportunity.

\section{Research Method and Data Collection}

\subsection{Data Collection and Sample}

The study is quantitative and selected area, is BRAC NGOs of Comilla and Chandpur districts of Bangladesh with having a time frame from 10 ${ }^{\text {th }}$ April 2019 to $15^{\text {th }}$ June2019.In these two districts, there are 45 BRAC's NGOs offices related with microcredit distribution and other programmes, among which authors have selected 26 offices as research population. In every office, authors considered general manager, assistant branch manager, cashier, field officer as the respondents of the study. Following known sample size formula prescribed by [92], authors have interviewed 260 employees through structured questionnaire format but later incomplete and untruthful responses were rejected, thus the 
study finalized 220 samples for this research.

The study followed a purposive sampling technique. One set of questionnaire with 18 items were administrated to collect data from the 260 respondents. Secondary data has been used also in this study for literature review and theoretical discussion. Response bias is the common phenomenon in social science research and to minimize this, authors were conscious about questionnaire design, question order, using best format, structure and order. The study further assessed the probability of non-response bias [93]. In this regard, two-tailed t-test has been used to examine variation between non-respondents and respondents in demographic variables (age, gender, designation and education). Therefore, non-response bias did not turn into big challenges in this study.

\subsection{Measurement Instruments}

A structured questionnaire consisting the key constructs of the research (job security, job innovativeness, internal communication, compassion $\&$ self-sacrifice, employee's satisfaction, and education \& training) was delivered among the respondents. The measurement instrument has been developed based on the prior literature. Five-point Likert scale from "strongly disagree" to "strongly agree" technique has been used for measuring the items of every construct. The construct job security has been measured using three items developed by the prior literature [94] with some modification in sentences structure. For the measurement of construct "internal communication", items have been adapted from the literature [87]. Job innovativeness was measured through three items from the literature [70]. The question items were used from the literature [95], to measure the construct compassion \& self-sacrifice. The moderating construct education $\&$ training was measured with the assistance of three questions items from the literature [96]. Finally, the dependent variable employee's satisfaction was measured following three items previously used in some researches [29] [97]. All of the items which have been used in this research to measure the constructs of the research model, were done based on the hints of previous literatures but it is the matter of trouble that no genuine assessment scale that directly matches with the present study was found for the constructs of this study. Therefore, a combined item has been adapted from the studies done in the context of job satisfaction, job service motivation, public service satisfaction.

\subsection{Data Analysis Method}

To analyse the data SPSS 21 and AMOS 22 version has been used. The questionnaire used in the study had been validated from the literature. However, its reliability and validity were examined by Cronbach and CFA. The analysis section of this paper included CFA, multiple regression analysis, and SEM. Confirmatory factor analysis initially extracted employee's job satisfaction, and multiple regression analysis identified the significant impact factors subsequently. Finally, structural equation modelling was used to verify the causal relationships between endogenous and exogenous constructs. 


\subsection{Results and Analysis}

In the present research, to review the reliability and validity test, the confirmatory factor analysis (CFA) observed which leads to the model testing where each of the hypotheses was challenged and reviewed [14]. The study used SPSS version 23 by IBM and SPSS-AMOS 21 by IBM to have statistical findings.

The findings of confirmatory factor analysis (CFA) that indicates to SEM related findings to measure the influence of several key factors for employee's satisfaction in NGOs sector of Bangladesh was discussed in the following first stage of the document.

In a nutshell, to discover the variables' relationships and to bring the validity of data for the purposes making results more reliable and valid, CFA assisted in showing the relational framework among the discussed set of variables. The Average Variance Extracted (AVE), Composite reliability (CR) and the Cronbach Alpha (CA) were enlisted and analysed in the eve of analysing the internal reliability of every variable and recorded as shown in Table 1.

The recorded values must be higher than 0.70, but in respect of AVE below 0.50 is also acceptable by [98]. Additionally, the values of factor loadings for every item were recorded in light of the standard values higher than 0.07 . In this study, researchers adapted the procedure of reliability testing from prior different empirical studies on employee/job satisfaction in government and private

Table 1. Confirmatory factor analysis (CFA) related findings.

\begin{tabular}{|c|c|c|c|c|c|}
\hline Variable & $\operatorname{Item}(s)$ & Loading & $a$ & CR & AVE \\
\hline \multirow{3}{*}{ Job Innovativeness (JI) } & JI1 & 0.875 & \multirow{3}{*}{0.735} & \multirow{3}{*}{0.852} & \multirow{3}{*}{0.658} \\
\hline & JI2 & 0.836 & & & \\
\hline & $\mathrm{JI} 3$ & 0.715 & & & \\
\hline \multirow{3}{*}{ Compassion \& Self-Sacrifice (CSS) } & CSS1 & 0.952 & \multirow{3}{*}{0.985} & \multirow{3}{*}{0.932} & \multirow{3}{*}{0.896} \\
\hline & CSS2 & 0.944 & & & \\
\hline & CSS3 & 0.944 & & & \\
\hline \multirow{3}{*}{ Job Security (JS) } & JS1 & 0.864 & \multirow{3}{*}{0.881} & \multirow{3}{*}{0.892} & \multirow{3}{*}{0.734} \\
\hline & JS2 & 0.860 & & & \\
\hline & JS3 & 0.847 & & & \\
\hline \multirow{3}{*}{ Internal Communication (IC) } & IC1 & 0.942 & \multirow{3}{*}{0.939} & \multirow{3}{*}{0.941} & \multirow{3}{*}{0.841} \\
\hline & IC2 & 0.914 & & & \\
\hline & IC3 & 0.895 & & & \\
\hline \multirow{3}{*}{ Education \& Training (ET) } & ET1 & 0.966 & \multirow{3}{*}{0.959} & \multirow{3}{*}{0.96} & \multirow{3}{*}{$0.90 s$} \\
\hline & ET2 & 0.962 & & & \\
\hline & ET3 & 0.933 & & & \\
\hline \multirow{3}{*}{ Employee Satisfaction (ES) } & ES1 & 0.887 & & \multirow{3}{*}{0.901} & \multirow{3}{*}{0.752} \\
\hline & ES2 & 0.861 & 0.887 & & \\
\hline & ES3 & 0.853 & & & \\
\hline
\end{tabular}


organization from various contextual perspectives [31] [91] [99]. Therefore, the authors established findings of this study as convergent reliable by previous some literature.

In Table 2, the result of means (m) and standard derivation (SD) is showed with having discriminant validity (DV) for every variable that shows latent variable correlation to assure the findings more valid as well as credible. Various aspects of respondent's views for any two variables are discussed with the assistance of discriminant validity (DV). In Table 2, AVE's square root value for every construct is cited in the diagonal row in order to make discriminant validity (DV) more reliable. The value of latent variable correlation should be lower than AVE's square root value in respect of every construct to make the data more credible and discriminatory reliable [100]. In a nutshell, we can claim that satisfactory and positive result can be found as showed in Table 3.

The path analysis, confirmatory factor analysis, and the fitness of the model were measured using Structural Equation Modelling [98]. In Table 3, the summary of the related index for model fitness evaluation has been shown. The value of $\mathrm{x}^{2}$ is 374.68 ; with value of $\mathrm{df}$ is 79 , calculated in the present study. Moreover, [101] suggested that the standard range of model fitness would be (1 - 3). [102] say that other relevant indexes only be preferred to study model fitness when $\mathrm{x}^{2}$

Table 2. Correlation analysis of observed variables.

\begin{tabular}{|c|c|c|c|c|c|c|c|c|}
\hline Variable (s) & Mean (M) & Standard Deviation (SD) & JI & CSS & JS & IC & ET & ES \\
\hline Job Innovativeness (JI) & 5.374 & 0.711 & 1 & & & & & \\
\hline Compassion \& self-sacrifice (CSS) & 5.048 & 1.463 & $0.219^{*}$ & 1 & & & & \\
\hline Job Security (JS) & 5.705 & 1.072 & $0.231^{\star}$ & 0.326 & 1 & & & \\
\hline Internal Communication (IC) & 4.676 & 1.298 & 0.007 & 0.366 & $0.201^{\star *}$ & 1 & & \\
\hline Education \& Training (ET) & 5.143 & 1.258 & 0.232 & 0.715 & 0.315 & 0.443 & 1 & \\
\hline Employee Satisfaction (ES) & 5.060 & 1.089 & $0.167^{\star}$ & 0.257 & $0.413^{\star}$ & 0.280 & $0.388^{\star}$ & 1 \\
\hline
\end{tabular}

Table 3. Summary of model fitness.

\begin{tabular}{cccc}
\hline Measuring Index & Observed Value In CFA & Observed Value In Model & Recommended Value \\
\hline CMIN & 374.68 & 306.85 & - \\
Df & 79 & 77 & Less than 3 \\
CMIN/df & 4.743 & 3.985 & Above 0.90, When factor loading is high (Hooper, 2008). \\
NFI & 0.949 & 0.958 & Above 0.90 Above 0.80 (Hu \& Bentler, 1999). \\
IFI & 0.959 & 0.968 & Less than 0.08 (Hooper, 2008) \\
TLI & 0.946 & 0.957 & Above 0.95 (Hu \& Bentler, 1999) \\
CFI & 0.959 & 0.968 & Above 0.95 (Hu \& Bentler, 1999). \\
RMSEA & 0.08 & 0.076 & Above 0.90 (Malaquias \& Hwang). \\
GFI & 0.916 & 0.932 & Above 0.95 (Hooper, 2008). \\
AGFI & 0.873 & 0.894 & \\
\hline
\end{tabular}


(Chi-square) is highly sensitive to the sample size. The non-centrality index includes values of (RMSEA and CFI), and fitness index includes the absolute value of (GFI and AGFI), relative (NFIand TLI). To measure the difference, the absolute fitness index does not use any one (alternate models \& the baselines). In generally, the standard value of GFI and AGFI is 0.90, but in current study, AGFI is 0.894 that moderately supported the findings. The value of NFI and TLI in the current study respectively is 0.958 and 0.968 that smarty supported by the literature [102] [103], while they suggested that both values should not below 0.95 . According to [102], for non-centrality index, the value of RSMEA (elaborates the discrepancy over the df) and CFI should be higher than 0.06 and lower than 0.09 and present study's RSMEA result is 0.076 that supported strongly the analysis of the study.

The value of AGFI is 0.894 in the present model, although it is lower than the standard value [103] but many previous empirical studies showed in their papers that values above $0.80 / 0.85$ are widely acceptable in social science research [104] [105] [106].

At the commencement of analysis, the maximum index of values could not be calculated as the standard values but later, with the help of modification index the variables' relations were examined until the fitness indices produced the desirable results and the least recommend values by the existing pool of literature, as a few of the fitness indices are discussed in Table 3 and the further details about incremental, parsimonious and absolute fit indices are following: 1) the measures for absolute fit as GFI, AGFI and RMSEA are 0.932, 0.894 and 0.076 respectively. Hence, the values of incremental fitness measures (RFI, IFI, CFI, and NFI) are 0.00, 0.968. 0.968 and 0.958 respectively. Finally, the values of $\mathrm{CMIN} / \mathrm{df}$ and parsimonious fits measured (PGFI, PNFI, PCFI) are respectively 3.985 and $0.00,0.000,0.00$, etc.

After examining the obtained model and identification of the model, the relationship among four exogenous (CSS, JC, JS, and JI) and two endogenous (EDU and ES) variables are tested and interpret near about $43 \%$ of the variance about employee satisfaction in NGOs, Bangladesh perspective. The outcomes of the examined hypothesis are narrated in the Table 4.

Table 4. Hypothesis evaluation and path analysis.

\begin{tabular}{ccccc}
\hline Hypothesis & Description & Beta (b) & Significance Value (s) & Result (s) \\
\hline H1 & $\mathrm{CSS}^{+} \rightarrow \mathrm{ATT}^{+}$ & 0.046 & 0.331 & Not Supported \\
$\mathrm{H} 2$ & $\mathrm{IC}^{+} \rightarrow \mathrm{ATT}^{+}$ & 0.193 & 0.000 & Supported \\
$\mathrm{H} 3$ & $\mathrm{JS}^{+} \rightarrow \mathrm{ATT}^{+}$ & 0.373 & 0.000 & Supported \\
$\mathrm{H} 4$ & $\mathrm{JI}^{+} \rightarrow \mathrm{ATT}^{+}$ & 0.138 & 0.000 & Supported \\
$\mathrm{H} 5 \mathrm{a}$ & $\mathrm{CSS}^{*} \mathrm{EDU} \rightarrow \mathrm{ATT}$ & 0.064 & 0.000 & Supported \\
$\mathrm{H} 5 \mathrm{~b}$ & $\mathrm{IC}^{*} \mathrm{EDU} \rightarrow \mathrm{ATT}$ & 0.054 & 0.000 & Supported \\
$\mathrm{H} 5 \mathrm{c}$ & $\mathrm{JS}{ }^{*} \mathrm{EDU} \rightarrow \mathrm{ATT}$ & 0.041 & 0.000 & Supported \\
$\mathrm{H} 5 \mathrm{~d}$ & $\mathrm{JI}{ }^{*} \mathrm{EDU} \rightarrow \mathrm{ATT}$ & 0.052 & 0.000 & Supported \\
\hline
\end{tabular}


Seven of the narrated hypothesis is supported by the examined model that includes $\mathrm{H} 2-\mathrm{H} 5 \mathrm{~d}$, whereas the relationship between compassion \& self-sacrifice and employee's satisfaction is not succeeded to identify the employee's satisfaction of NGOs in Bangladesh. In the discussion phase, every hypothesis has been discussed as well as reviewed in light of prevailing secondary literature.

\section{Result Discussion}

The objective of this study is to explore the effects of some factors on employee's satisfaction in NGOs sectors in Bangladesh. By analysis-job innovativeness, job security, and internal communication lead to employee's satisfaction of NGOs in Bangladesh, but compassion \& self-sacrifice does not affect employee's satisfaction. Path analysis of result part explored that the moderator constructs education \& training moderated relationship-employee satisfaction to-job innovativeness, job security, internal communication, and compassion \& self-sacrifice.

The higher "Job Security" (JS) increases the "Employee's Satisfaction" (ES) in the case of NGOs is supported by path coefficient analysis, indicating that job security brings employee's satisfaction in NGOs sectors. The findings of previous some researches similarly supported that job security play a key role for employee's satisfaction in different context [40] [55], but few studies are not agreed that only job satisfaction is influencing factors for bringing satisfaction in NGOs sectors [59]. The authors predict based on analysis and literature reviews that employee's satisfaction depends on job security in a large extent.

The higher constructive "Internal Communication" (IC) increases the "Employee's Satisfaction" (ES) in NGOs is supported by the path coefficient analysis of the current study, referring that internal communication effects on employee's satisfaction in NGOs sectors. Accordingly to [63], the result is supported with no differences. Based on the findings and literature study authors predict that internal communication among employees, employees, and employers play strong role to make satisfied the employees.

The higher "Job Innovativeness" (JI) increases the "Employee's Satisfaction" (ES) in NGOs in the case of Bangladesh is supported by the path coefficient analysis of the present study, whereas it illustrated that job innovativeness significantly impact on employee's satisfaction. The findings are consistent, having no variation with previous some published works [30] [67]. Moreover, authors foretell from findings and theoretical discussion that job innovativeness fetches tangible satisfaction among employees.

The higher degree of "Compassion" (Com) increases the "Employee's Satisfaction" (ES), and the greater value of "Self Sacrifice" (SS) increases the "Employee's Satisfaction" (ES) in NGOs in Bangladesh are not supported by the path coefficient analysis of this current study. The findings are not similar to many of the previous studies [73] [74] [95]. Although, these studies investigated that compassion is an organizational motivational instrument and self-sacrifice is individual's self-enthusiastic instrument to be content in an organization. Moreover, the authors figure out that compassion and self-sacrifice can moderately 
act for bringing employee's satisfaction in NGOs sectors.

The attribute of "Training and Education" moderates the determining power of "job characteristics" (Job innovativeness, Job security and Internal communication) and "public service motivational factors" (self-sacrifice and compassion) while defining and explaining "Employees satisfaction" (ES) is strongly supported by the path coefficient analysis of this study. Although, no direct study's findings found with similar and dissimilar results, but authors predict that education and training facilities for the development of employees can affect on other factors those which brings satisfaction and employee's satisfaction.

\section{Conclusions}

In conformity with this research, authors sum up that not only job innovativeness, job security, and internal communication make contented the employees but also the stimulating elements for self-development in the career of the employees leads to employee's satisfaction in NGOs sectors in Bangladesh. Although, a motivational ingredient like compassion \& self-sacrifice was proved in several prior studies with evidence that it positively affects an employee's satisfaction in different contextual aspects, but this study could not prove statistically. In this point, the theoretical as well as practical implications, loopholes, future directions, and recommendations-is more consistent for illustration in the current study.

The followings are the theoretical implications of this study: the majority of the past studies on employee's satisfaction highlighted on the motivating factors of employee's satisfaction like salary, promotion, rewards etc. and investigated employee's satisfaction from the perspective of government employee's satisfaction, employee's satisfaction in business sectors, teaching institute employee's satisfaction and health sectors employee's satisfaction [27] [28]. No one researched the employee's satisfaction in respect of NGOs sectors of Bangladesh. A previous study investigated job security as a momentous factor in Bangladesh for satisfying employees in the job because of large rate of unemployment (Masum et al., 2015). The study explores how three factors (job innovativeness, job security, and internal communication) contribute to ES by bluntly considering the essence of employee satisfaction theory. Moreover, the construct education and training have been added newly in employee's satisfaction theory to get more ES outcomes in NGOs sectors in Bangladesh. Particularly, examining the moderating role of ET offers new insights to ES related studies. Furthermore, the NGOs, as well as the private, corporate organizations, government organizations of Bangladesh, can apply the outcomes of this research to diminish employees turn over, getting best performances from employees especially through focusing on moderating construct. Practically, the study indicates empirically which factors should be addressed for ES in NGOs sectors.

In light of the findings of this research, firstly: authors suggested that employers of NGOs working in Bangladesh should cordially focus on satisfactory em- 
ployee factors for the sake of assuring better performance and productivity because a dissatisfied employee might not be affordable to keep abreast with organizational expectation for targeted outcomes. Secondly, a periodic performance evaluation system and the psychological test should be arranged to comprehend the level of satisfaction and performance of the employees.

\section{Limitation and Future Directions}

The study also could not avoid limitations. Authors conducted this research based on one NGO that cannot represent the whole NGOs working in Bangladesh due to nature of work, size, employee number, and location. The study focused only five factors affecting ES in NGOs sectors, but some more crucial factors like salary, justice, reward, code of conduct, work environment, and promotion were disregarded.

In the future direction section, the study suggests the following directions: firstly, it proposes to conduct the mixed method approach because only qualitative or quantitative research cannot cover the complete sense of understanding regarding ES. Truly, respondents cannot opinion fully in closed-ended questionnaire style.

\section{Acknowledgements}

We acknowledge professor Song Wei and his assistant Dr. Zhaoshu Liang for their essential suggestions, comments in respect of research topic selection, research designing. We are especially grateful to Dr. Fahad Asmi for providing a guideline in case of statistical analysis.

\section{Conflicts of Interest}

The authors declare no conflicts of interest regarding the publication of this paper.

\section{References}

[1] Tomaževič, N., Seljak, J. and Aristovnik, A. (2014) Factors Influencing Employee Satisfaction in the Police Service: The Case of Slovenia. Personnel Review, 43, 209-227. https://doi.org/10.1108/PR-10-2012-0176

[2] Rahman, M.M. (2002) Problems of the NGOs in Housing the Urban Poor in Bangladesh. Habitat International, 26, 433-451. https://doi.org/10.1016/S0197-3975(02)00017-6

[3] Aguiar do Monte, P. (2012) Job Dissatisfaction and Labour Turnover: Evidence from Brazil. The International Journal of Human Resource Management, 23, 1717-1735. https://doi.org/10.1080/09585192.2011.605071

[4] Sanders, B., Phillips, J. and Vanreusel, B. (2014) Opportunities and Challenges Facing NGOs Using Sport as a Vehicle for Development in Post-Apartheid South Africa. Sport, Education and Society, 19, 789-805. https://doi.org/10.1080/13573322.2012.711304

[5] Maiers, C., Reynolds, M. and Haselkorn, M. (2005) Challenges to Effective Informa- 
tion and Communication Systems in Humanitarian Relief Organizations. IPCC 2005. Proceedings. International Professional Communication Conference, Limerick, Ireland, 10-13 July 2005, 82-91.

[6] Hossan, C.G., Sarker, M.A.R. and Afroze, R. (2012) Recent Unrest in the RMG Sector of Bangladesh: Is This an Outcome of Poor Labour Practices? International Journal of Business and Management, 7, 206. https://doi.org/10.5539/ijbm.v7n3p206

[7] Simatwa, E. (2011) Job Satisfaction and Dissatisfaction among Teachers in Kenya. Kenya Journal of Education Planning Economics and Management, 3, 114-123.

[8] Oshagbemi, T. (1996) Job Satisfaction of UK Academics. Educational Management \& Administration, 24, 389-400. https://doi.org/10.1177/0263211X9602400405

[9] Mello, J.A. (2014) Strategic Human Resource Management. Nelson Education, Toronto.

[10] Bigliardi, B., Petroni, A. and Ivo Dormio, A. (2005) Organizational Socialization, Career Aspirations and Turnover Intentions among Design Engineers. Leadership \& Organization Development Journal, 26, 424-441. https://doi.org/10.1108/01437730510617645

[11] Hackman, J.R. and Oldham, J.R. (1975) Development of the Job Diagnostic Survey. Journal of Applied Psychology, 60, 159-170. https://doi.org/10.1037/h0076546

[12] Kanfer, R. (1990) Motivation Theory and Industrial and Organizational Psychology. Handbook of Industrial and Organizational Psychology, 1, 75-130.

[13] Judge, T.A., et al. (2001) The Job Satisfaction-Job Performance Relationship: A Qualitative and Quantitative Review. Psychological Bulletin, 127, 376.

[14] Anderson, J.C. and Gerbing, D.W. (1988) Structural Equation Modeling in Practice: A Review and Recommended Two-Step Approach. Psychological Bulletin, 103, 411-423. https://doi.org/10.1037/0033-2909.103.3.411

[15] Cotton, J.L. and Tuttle, J.M. (1986) Employee Turnover: A Meta-Analysis and Review with Implications for Research. Academy of Management Review, 11, 55-70. https://doi.org/10.5465/amr.1986.4282625

[16] Kuo, H.T., Lin, K.C. and Li, I.C. (2014) The Mediating Effects of Job Satisfaction on Turnover Intention for Long-Term Care Nurses in Taiwan. Journal of Nursing Management, 22, 225-233. https://doi.org/10.1111/jonm.12044

[17] Diaz-Serrano, L. and Cabral Vieira, J.A. (2005) Low Pay, Higher Pay and Job Satisfaction within the European Union: Empirical Evidence from Fourteen Countries. IZA Discussion Paper No. 1558.

[18] Miller, H.E. and Rosse, J.G. (2002) Emotional Reserve and Adaptation to Job Dissatisfaction. In: Brett, J.M. and Drasgow, F., Eds., The Psychology of Work. Theoretically Based Empirical Research, Lawrence Erlbaum Associates Publishers, Mahwah, NJ, 205-231.

[19] D'angelo, S., et al. (2016) Job Dissatisfaction and the Older Worker: Baseline Findings from the Health and Employment after Fifty Study. Occupational and Environmental Medicine, 73, 512-519. https://doi.org/10.1136/oemed-2016-103591

[20] Jiang, B., Baker, R.C. and Frazier, G.V. (2009) An Analysis of Job Dissatisfaction and Turnover to Reduce Global Supply Chain Risk: Evidence from China. Journal of Operations Management, 27, 169-184. https://doi.org/10.1016/j.jom.2007.09.002

[21] Yousef, D.A. (2000) Organizational Commitment: A Mediator of the Relationships of Leadership Behavior with Job Satisfaction and Performance in a Non-Western Country. Journal of Managerial Psychology, 15, 6-24. 
https://doi.org/10.1108/02683940010305270

[22] Dole, C. and Schroeder, R.G. (2001) The Impact of Various Factors on the Personality, Job Satisfaction and Turnover Intentions of Professional Accountants. Managerial Auditing Journal, 16, 234-245. https://doi.org/10.1108/02686900110389188

[23] Emoja, M.M. (2016) Job Satisfaction and Teacher Turnover Intention in Secondary Schools in Kakamega Central District, Kenya. International Journal of Education and Research, 4, 85-100.

[24] Lambert, E.G., Hogan, N.L. and Barton, S.M. (2001) The Impact of Job Satisfaction on Turnover Intent: A Test of a Structural Measurement Model Using a National Sample of Workers. The Social Science Journal, 38, 233-250. https://doi.org/10.1016/S0362-3319(01)00110-0

[25] Akter, A., et al. (2017) Factors Affecting Job Satisfaction of Working Mothers of Readymade Garments Sector in Bangladesh. Issues in Business Management and Economics, 5, 25-36.

[26] Kemelgor, B.H. and Meek, W.R. (2008) Employee Retention in Growth-Oriented Entrepreneurial Firms: An Exploratory Study. Journal of Small Business Strategy, 19, 55-68.

[27] Chen, S.-H., et al. (2006) The Development of an Employee Satisfaction Model for Higher Education. The TQM Magazine, 18, 484-500. https://doi.org/10.1108/09544780610685467

[28] Yildirim, S., Acaray, A. and Aydin, K. (2017) Exploring the Impact of Marketing Culture on Job Satisfaction: Evidence from the Turkish Banking Sector. World Journal of Entrepreneurship, Management and Sustainable Development, 13, 151-162. https://doi.org/10.1108/WJEMSD-01-2017-0001

[29] Nwachukwu, C.E. and Chladková, H. (2017) Human Resource Management Practices and Employee Satisfaction in Microfinance Banks in Nigeria. Trends Economics and Management, 11, 23-35. https://doi.org/10.13164/trends.2017.28.23

[30] Karyotakis, K.M. and Moustakis, V.S. (2016) Organizational Factors, Organizational Culture, Job Satisfaction and Entrepreneurial Orientation in Public Administration. The European Journal of Applied Economics, 13, 47-59. https://doi.org/10.5937/ejae13-10781

[31] Agho, A.O., Mueller, C.W. and Price, J.L. (1993) Determinants of Employee Job Satisfaction: An Empirical Test of a Causal Model. Human Relations, 46, 1007-1027. https://doi.org/10.1177/001872679304600806

[32] Javed, M., et al. (2012) Impact of HR Practices on Employee Job Satisfaction in Public Sector Organizations of Pakistan. Interdisciplinary Journal of Contemporary Research in business, 4, 348-363.

[33] Martin, M. and Kaufman, E. (2013) Do Job Satisfaction and Commitment to Organization Matter When It Comes to Retaining Employees. Journal of Extension, $51,29$.

[34] Ovadje, F. (2009) Exploring Turnover among Middle Managers in a Non-Western Context. International Journal of Business Research, 10, 64-80.

[35] Spector, P.E. (1985) Measurement of Human Service Staff Satisfaction: Development of the Job Satisfaction Survey. American Journal of Community Psychology, 13, 693-713. https://doi.org/10.1007/BF00929796

[36] Al-Takroni, H., Al-Hindi, A., Joshva, K. and Al-Harbi, A. (2018) Job Satisfaction among Nurses in Al-Qassim Hospitals and Primary Health Care Centers, Saudi Arabia, 2016. International Journal of Advanced Nursing Studies, 7, 34-38. 
https://doi.org/10.14419/ijans.v7i1.8864

[37] Gosse, B. and Hurson, C. (2016) Assessment and Improvement of Employee Job-Satisfaction: A Full-Scale Implementation of Musa Methodology on Newly Recruited Personnel in a Major French Organisation. Annals of Operations Research, 247, 657-675. https://doi.org/10.1007/s10479-015-1811-y

[38] Mia, M.N. (2017) Measurement of Job Satisfaction of Government Bankers: An Empirical Study on Sonali Bank Ltd. Management, 31, 1.

[39] Hossain, M.M. (2000) Job Satisfaction of Commercial Bank Employees in Bangladesh: A Comparative Study of Private and Public Sectors. Indian Journal of Industrial Relations, 35, 347-361.

[40] Masum, A.K.M., Azad, M.A.K. and Beh, L.-S. (2015) Determinants of Academics' Job Satisfaction: Empirical Evidence from Private Universities in Bangladesh. PLoS ONE, 10, e0117834. https://doi.org/10.1371/journal.pone.0117834

[41] Ashraf, M.A., Joarder, M. and Al-Masum, R. (2008) Job Satisfaction of the Employees in the Mobile Phone Corporates in Bangladesh: A Case Study. American International University-Bangladesh (AIUB), Bangladesh.

[42] Fosam, E., Grimsley, M. and Wisher, S. (1998) Exploring Models for Employee Satisfaction with Particular Reference to a Police Force. Total Quality Management, 9, 235-247. https://doi.org/10.1080/0954412989090

[43] Abdulla, J., Djebarni, R. and Mellahi, K. (2011) Determinants of Job Satisfaction in the UAE: A Case Study of the Dubai Police. Personnel Review, 40, 126-146. https://doi.org/10.1108/00483481111095555

[44] Balc1, F. (2011) The Effects of Education on Police Officer Job Satisfaction: The Case of Turkish National Police. Journal of Human Sciences, 8, 265-285.

[45] Bipp, T. and Kleingeld, A. (2011) Goal-Setting in Practice: The Effects of Personality and Perceptions of the Goal-Setting Process on Job Satisfaction and Goal Commitment. Personnel Review, 40, 306-323. https://doi.org/10.1108/00483481111118630

[46] Chiva, R. and Alegre, J. (2008) Emotional Intelligence and Job Satisfaction: The Role of Organizational Learning Capability. Personnel Review, 37, 680-701. https://doi.org/10.1108/00483480810906900

[47] Garland, B.E., McCarty, W.P. and Zhao, R. (2009) Job Satisfaction and Organizational Commitment in Prisons: An Examination of Psychological Staff, Teachers, and Unit Management Staff. Criminal Justice and Behavior, 36, 163-183. https://doi.org/10.1177/0093854808327343

[48] Kakar, S. (2002) Gender and Police Officers' Perceptions of Their Job Performance: An Analysis of the Relationship between Gender and Perceptions of Job Performance. Criminal Justice Policy Review, 13, 238-256. https://doi.org/10.1177/0887403402133003

[49] Ortega, A., Brenner, S.-O. and Leather, P. (2007) Occupational Stress, Coping and Personality in the Police: An SEM Study. International Journal of Police Science \& Management, 9, 36-50. https://doi.org/10.1350/ijps.2007.9.1.36

[50] Metle, M.A.K. (2003) The Impact of Education on Attitudes of Female Government Employees. Journal of Management Development, 22, 603-626. https://doi.org/10.1108/02621710310484759

[51] Boothby, J.L. and Clements, C.B. (2002) Job Satisfaction of Correctional Psychologists: Implications for Recruitment and Retention. Professional Psychology: Research and Practice, 33, 310-315. https://doi.org/10.1037//0735-7028.33.3.310

[52] Johnson, R.R. (2012) Police Officer Job Satisfaction: A Multidimensional Analysis. 
Police Quarterly, 15, 157-176. https://doi.org/10.1177/1098611112442809

[53] Carlan, P.E. (2007) The Search for Job Satisfaction: A Survey of Alabama Policing. American Journal of Criminal Justice, 32, 74-86. https://doi.org/10.1007/s12103-007-9014-y

[54] Noblet, A., Rodwell, J. and Allisey, A. (2009) Job Stress in the Law Enforcement Sector: Comparing the Linear, Non-Linear and Interaction Effects of Working Conditions. Stress and Health: Journal of the International Society for the Investigation of stress, 25, 111-120. https://doi.org/10.1002/smi.1227

[55] Artz, B. and Kaya, I. (2014) The Impact of Job Security on Job Satisfaction in Economic Contractions versus Expansions. Applied Economics, 46, 2873-2890. https://doi.org/10.1080/00036846.2014.914148

[56] Roy, A., van der Weijden, T. and de Vries, N. (2017) Relationships of Work Characteristics to Job Satisfaction, Turnover Intention, and Burnout among Doctors in the District Public-Private Mixed Health System of Bangladesh. BMC Health Services Research, 17, Article No. 421. https://doi.org/10.1186/s12913-017-2369-y

[57] Bolt, J.F. (1983) Job Security-Its Time Has Come. Harvard Business Review, 61, 115-123.

[58] Koustelios, A., Kouli, O. and Theodorakis, N. (2003) Job Security and Job Satisfaction among Greek Fitness Instructors. Perceptual and Motor Skills, 97, 192-194. https://doi.org/10.2466/pms.2003.97.1.192

[59] Wilczyńska, A., Batorski, D. and Sellens, J.T. (2016) Employment Flexibility and Job Security as Determinants of Job Satisfaction: The Case of Polish Knowledge Workers. Social Indicators Research, 126, 633-656. https://doi.org/10.1007/s11205-015-0909-6

[60] Theodossiou, I. and Vasileiou, E. (2007) Making the Risk of Job Loss a Way of Life: Does It Affect Job Satisfaction? Research in Economics, 61, 71-83. https://doi.org/10.1016/j.rie.2007.03.002

[61] Manojlovich, M. (2005) Linking the Practice Environment to Nurses' Job Satisfaction through Nurse-Physician Communication. Journal of Nursing Scholarship, 37, 367-373. https://doi.org/10.1111/j.1547-5069.2005.00063.x

[62] Raina, R. and Roebuck, D.B. (2016) Exploring Cultural Influence on Managerial Communication in Relationship to Job Satisfaction, Organizational Commitment, and the Employees' Propensity to Leave in the Insurance Sector of India. International Journal of Business Communication, 53, 97-130. https://doi.org/10.1177/2329488414525453

[63] Smith, S.A., Patmos, A. and Pitts, M.J. (2018) Communication and Teleworking: A Study of Communication Channel Satisfaction, Personality, and Job Satisfaction for Teleworking Employees. International Journal of Business Communication, 55, 44-68. https://doi.org/10.1177/2329488415589101

[64] Euske, N.A. and Roberts, K.H. (1987) Evolving Perspectives in Organization Theory: Communication Implications. In: Jablin, F.M., Putnam, L.L., Roberts, K.H. and Porter, L.W., Eds., Handbook of Organizational Communication: An Interdisciplinary Perspective, Sage Publications, Inc., Thousand Oaks, CA, 41-69.

[65] Alam, A.A.S. (2016) Communication Satisfaction: A Study on Junior Executives Working in Private Sector of Bangladesh. Journal of Business and Technology (Dhaka), 11, 69-90. https://doi.org/10.3329/jbt.v11i1.34243

[66] Uddin, M.K., Akther, S. and Tumpa, A.S. (2016) Factors Influencing Job Satisfaction of Employees: A Study on Telecommunication Sector of Bangladesh. European 
Journal of Business and Management, 8, 57-64.

[67] Dobni, C.B. (2008) Measuring Innovation Culture in Organizations: The Development of a Generalized Innovation Culture Construct Using Exploratory Factor Analysis. European Journal of Innovation Management, 11, 539-559. https://doi.org/10.1108/14601060810911156

[68] Iranmanesh, M., Zailani, S., Moeinzadeh, S. and Nikbin, D. (2017) Effect of Green Innovation on Job Satisfaction of Electronic and Electrical Manufacturers' Employees through Job Intensity: Personal Innovativeness as Moderator. Review of Managerial Science, 11, 299-313. https://doi.org/10.1007/s11846-015-0184-6

[69] Al-Mahayreh, M. and Abdel-Qader, M. (2015) The Effect of the Factors Leading to Job Satisfaction on the Innovation Level: Study on Workers in Islamic Banks Operating in Jordan. International Journal of Business, Humanities and Technology, 5, 24-39.

[70] Bysted, R. (2013) Innovative Employee Behaviour: The Moderating Effects of Mental Involvement and Job Satisfaction on Contextual Variables. European Journal of Innovation Management, 16, 268-284. https://doi.org/10.1108/EJIM-09-2011-0069

[71] Wei, Y., O’Neill, H., Lee, R.P. and Zhou, N. (2013) The Impact of Innovative Culture on Individual Employees: The Moderating Role of Market Information Sharing. Journal of Product Innovation Management, 30, 1027-1041. https://doi.org/10.1111/j.1540-5885.2012.01000.x

[72] Radey, M. and Figley, C.R. (2007) The Social Psychology of Compassion. Clinical Social Work Journal, 35, 207-214. https://doi.org/10.1007/s10615-007-0087-3

[73] Benzo, R.P., Kirsch, J.L. and Nelson, C. (2017) Compassion, Mindfulness, and the Happiness of Healthcare Workers. Explore, 13, 201-206.

https://doi.org/10.1016/j.explore.2017.02.001

[74] Lee, Y. and Seomun, G. (2016) Role of Compassion Competence among Clinical Nurses in Professional Quality of Life. International Nursing Review, 63, 381-387. https://doi.org/10.1111/inr.12295

[75] Perry, J.L., et al. (2008) What Drives Morally Committed Citizens? A Study of the Antecedents of Public Service Motivation. Public Administration Review, 68, 445-458. https://doi.org/10.1111/j.1540-6210.2008.00881.x

[76] Camilleri, E. (2007) Antecedents Affecting Public Service Motivation. Personnel Review, 36, 356-377. https://doi.org/10.1108/00483480710731329

[77] Beach, S.R. and Tesser, A. (1993) Decision Making Power and Marital Satisfaction: A Self-Evaluation Maintenance Perspective. Journal of Social and Clinical Psychology, 12, 471-494. https://doi.org/10.1521/jscp.1993.12.4.471

[78] Akareem, H.S. and Hossain, S.S. (2016) Determinants of Education Quality: What Makes Students' Perception Different? Open Review of Educational Research, 3, 52-67. https://doi.org/10.1080/23265507.2016.1155167

[79] Belfield, C.R. and Harris, R.D. (2002) How Well Do Theories of Job Matching Explain Variations in Job Satisfaction across Education Levels? Evidence for UK Graduates. Applied Economics, 34, 535-548. https://doi.org/10.1080/00036840110041895

[80] Green, F. and Zhu, Y. (2010) Overqualification, Job Dissatisfaction, and Increasing Dispersion in the Returns to Graduate Education. Oxford Economic Papers, 62, 740-763. https://doi.org/10.1093/oep/gpq002

[81] Pichler, F. and Wallace, C. (2008) What Are the Reasons for Differences in Job Satisfaction across Europe? Individual, Compositional, and Institutional Explanations. 
European Sociological Review, 25, 535-549. https://doi.org/10.1093/esr/jcn070

[82] Castellacci, F. and Viñas-Bardolet, C. (2019) Internet Use and Job Satisfaction. Computers in Human Behavior, 90, 141-152.

https://doi.org/10.1016/j.chb.2018.09.001

[83] Gürbüz, A. (2007) An Assessment on the Effect of Education Level on the Job Satisfaction from the Toursim Sector Point of View. Doğuş Üniversitesi Dergisi, 8, 36-46 https://doi.org/10.31671/dogus.2019.240

[84] Dessler, G. (2006) A Framework for Human Resource Management. Pearson Education India, Bengaluru.

[85] Schmidt, S.W. (2007) The Relationship between Satisfaction with Workplace Training and Overall Job Satisfaction. Human Resource Development Quarterly, 18, 481-498. https://doi.org/10.1002/hrdq.1216

[86] Castro, M.L. and Martins, N. (2010) The Relationship between Organisational Climate and Employee Satisfaction in a South African Information and Technology Organization. SA Journal of Industrial Psychology, 36, 1-9. https://doi.org/10.4102/sajip.v36i1.800

[87] Matthies-Baraibar, C., et al. (2014) Is Organizational Progress in the EFQM Model Related to Employee Satisfaction? BMC Health Services Research, 14, 468. https://doi.org/10.1186/1472-6963-14-468

[88] Spector, P.E. (1997) Job Satisfaction: Application, Assessment, Causes, and Consequences. Sage Publications, [Thousand Oaks, CA. https://doi.org/10.4135/9781452231549

[89] Origo, F. and Pagani, L. (2009) Flexicurity and Job Satisfaction in Europe: The Importance of Perceived and Actual Job Stability for Well-Being at Work. Labour Economics, 16, 547-555. https://doi.org/10.1016/j.labeco.2009.02.003

[90] Vlosky, R.P. and Aguilar, F.X. (2009) A Model of Employee Satisfaction: Gender Differences in Cooperative Extension. Journal of Extension, 47, 1-15.

[91] Navimipour, N.J. and Zareie, B. (2015) A Model for Assessing the Impact of e-Learning Systems on Employees' Satisfaction. Computers in Human Behavior, 53, 475-485. https://doi.org/10.1016/j.chb.2015.07.026

[92] Yamane, T. (1973) Statistics: An Introductory Analysis. 3rd Edition, Harper and Row, New York.

[93] Armstrong, J.S. and Overton, T.S. (1977) Estimating Nonresponse Bias in Mail Surveys. Journal of Marketing Research, 14, 396-402. https://doi.org/10.1177/002224377701400320

[94] Oldham, G.R., Kulik, C.T., Stepina, L.P. and Ambrose, M.L. (1986) Relations between Situational Factors and the Comparative Referents Used by Employees. Academy of Management Journal, 29, 599-608. https://doi.org/10.5465/256226

[95] Kim, S. (2016) Job Characteristics, Public Service Motivation, and Work Performance in Korea. Gestion et Management Public, 5, 7-24.

[96] Davis, M.H. (2018) Empathy: A Social Psychological Approach. Routledge, London. https://doi.org/10.4324/9780429493898

[97] Blanz, M. (2017) Employees' Job Satisfaction: A Test of the Job Characteristics Model among Social Work Practitioners. Journal of Evidence-Informed Social Work, 14, 35-50. https://doi.org/10.1080/23761407.2017.1288187

[98] Hair, J.F., Black, W.C., Babin, B.J. and Anderson, R.E. (2006) Multivariate Data Analysis. Pearson Prentice Hall, Upper Saddle River, NJ.

[99] Penger, S. and Černe, M. (2014) Authentic Leadership, Employees’ Job Satisfaction, 
and Work Engagement: A Hierarchical Linear Modelling Approach. Economic Research-Ekonomska istraživanja, 27, 508-526.

https://doi.org/10.1080/1331677X.2014.974340

[100] Chin, W.W. (1998) Commentary: Issues and Opinion on Structural Equation Modeling. MIS Quarterly, 22, 7-41.

[101] Chin, W.W. and Todd, P.A. (1995) On the Use, Usefulness, and Ease of Use of Structural Equation Modeling in MIS Research: A Note of Caution. MIS Quarterly, 19, 237-246. https://doi.org/10.2307/249690

[102] Hooper, D., Coughlan, J. and Mullen, M. (2008) Structural Equation Modelling: Guidelines for Determining Model Fit. Electronic Journal of Business Research Methods, 6, 1-8.

[103] Hu, L.T. and Bentler, P.M. (1999) Cutoff Criteria for Fit Indexes in Covariance Structure Analysis: Conventional Criteria versus New Alternatives. Structural Equation Modeling: A Multidisciplinary Journal, 6, 1-55. https://doi.org/10.1080/10705519909540118

[104] Al-Hujran, O., Al-Debei, M.M., Chatfield, A. and Migdadi, M. (2015) The Imperative of Influencing Citizen Attitude toward e-Government Adoption and Use. Computers in Human Behavior, 53, 189-203. https://doi.org/10.1016/j.chb.2015.06.025

[105] Bélanger, F. and Carter, L. (2008) Trust and Risk in e-Government Adoption. The Journal of Strategic Information Systems, 17, 165-176. https://doi.org/10.1016/j.jsis.2007.12.002

[106] Malaquias, R.F. and Hwang, Y. (2016) An Empirical Study on Trust in Mobile Banking: A Developing Country Perspective. Computers in Human Behavior, 54, 453-461. https://doi.org/10.1016/j.chb.2015.08.039 